\title{
LETTER
}

\section{Letter in Response to the Review by De Maria et al. 2014}

Baljinder Johal $\cdot$ Markus Howald $\cdot$ Manfred Fischer •

Jonathan Marshall $\cdot$ Geraldine Venthoye

To view enhanced content go to www.combitherapy-open.com

Received: April 28, 2014

(C) The Author(s) 2014. This article is published with open access at Springerlink.com

Dear Editor,

We would like to clarify some points about the DIFFUSE (Defining fluticasone propionate/ formoterol particulate size) study (December 2013, p 39) [1] in light of the recent review by De Maria and colleagues [2]. Our in vitro study assessed the effects of inhalation flow rate on the aerodynamic particle size distribution (APSD) of fluticasone propionate/formoterol pMDI (FP/FORM; flutiform ${ }^{\circledR}$, Jagotec AG, Muttenz, Switzerland) compared with three other ICS/LABA combinations: fluticasone propionate/salmeterol DPI (FP/SAL; Seretide ${ }^{\circledR}$ Accuhaler $^{\circledR}$, GlaxoOperations UK Ltd, Herts, UK), budesonide/formoterol DPI (BUD/FORM; Symbicort $^{\circledR}$ Turbohaler $^{\circledR}$, AstraZeneca AB,

\section{B. Johal ( $\square)$}

Mundipharma Research Limited, Cambridge

Science Park, Milton Road, Cambridge CB4 0GW, UK

e-mail: Baljinder.Johal@mundipharma-rd.eu

M. Howald · M. Fischer - G. Venthoye

Skyepharma AG, Eptingerstrasse 61, 4132 Muttenz, Switzerland

J. Marshall

Mundipharma International Limited, Cambridge

Science Park, Milton Road, Cambridge CB4 OAB, UK
Södertälje, Sweden) and beclometasone dipropionate/formoterol pMDI (BDP/FORM; Foster $^{\mathrm{TM}}$, Chiesi Farmaceutici S.p.A, Parma, Italy) [1].

Contrary to the suggestions in the review, the patient information leaflets for FP/FORM and BDP/FORM do not specify a flow rate or 'a long breath' $[3,4]$. Inhalation flow rates of $30-60 \mathrm{~L} / \mathrm{min}$ are recognised as 'clinically effective' for pMDIs and DPIs, according to the In-Check DIAL [5]. pMDIs are active aerosols with relatively low resistance, and patients often use them at flow rates $>30 \mathrm{~L} / \mathrm{min}$ [6-8]. Hence, the flow rate dependency of inhalers is of interest to physicians as well as regulators. Including a faster flow rate of $60 \mathrm{~L} / \mathrm{min}$ in our study was therefore appropriate, and is relevant to the real-life use of these inhalers.

All inhalers were tested across pre-defined parameters, using the same apparatus and the same ambient conditions, to ensure a fair and appropriate comparison. The review questions the use of an Andersen Cascade Impactor (ACI): an ACI is arguably the most widely used tool for testing inhalers, and is routinely used at flow rates of 30, $60 \mathrm{~L} / \mathrm{min}$, and above [9-14]. Indeed, the authors of the review have themselves used 
an ACI to assess pMDIs at flow rates of 30 and $60 \mathrm{~L} / \mathrm{min}[9,15]$.

Importantly, we adapted and calibrated the ACI for use at $60 \mathrm{~L} / \mathrm{min}$ (as recommended by the European Pharmacopoeia [16]), although this was unclear in our paper. Following standard practice, stages 0 and 7 were removed, and new stages ( -0 and -1$)$ were added, providing 'target cut-points' for $60 \mathrm{~L} /$ min with the same particle size cut-off diameters as for $30 \mathrm{~L} / \mathrm{min}$ [17].

The review suggests that a 'low-dose number' and uncoated ACI plates may have led to an underestimation of BDP/FORM particle size information. Bouncing and consequent re-entrainment of particles might affect assessment of particle size for solid particles impacting onto ACI stages, and the effect is particularly pronounced for high-payload powder presentations and can lead to an overestimation of fine particles. Hence, the plates were coated with surfactant when testing the two DPIs [1], as recommended by the European Pharmacopoeia. Coating may be not necessary for testing pMDIs $[16,17]$ and is not required for FP/FORM pMDI, but we accept the possibility that uncoated plates could lead to an overestimation of extra-fine particles for BDP/FORM solution and therefore an underestimation of the Mass Median Aerodynamic Diameter (MMAD). This may explain the high Geometric Standard Deviation (GSD) for BDP/FORM at $60 \mathrm{~L} / \mathrm{min}$; further work is needed to understand this. However and importantly, uncoated plates would not lead to an underestimation of the fine particle fraction (FPF) nor explain the flow rate dependent effects of the FPF for BDP/FORM.

Internal qualification of the methods confirmed that the number of actuations (i.e. discharges) did not affect the results. The number of discharges was limited in accordance with the Pharmacopoeias, to avoid build-up effects and to align the number of discharges with the dose received by the patient, as closely as was acceptable for analysis. Moreover, the total amount of drug recovered from all stages, including from the ACI induction port, was within USP limits.

Contrary to the suggestion in the review, comparing the FPFs of different ICSs is entirely acceptable, in fact the authors of the review have also done such a comparison [9]. There is no reason why the APSDs of FP/FORM and BDP/ FORM cannot be compared accurately and reliably; the amount of each drug component deposited at each ACI stage was analysed using established methods specific to each of the individual chemical entities in each presentation. For each product, the FPF of the LABA showed the same pattern as for the ICS; as both products contain similar doses of the same LABA (formoterol), it seems unlikely that the assay would underestimate the dose of formoterol emitted by the BDP/FORM device, but not by FP/FORM.

The review authors also query whether it is appropriate to express the FPF as a percentage of the labelled (or total) dose. For regulatory purposes, the FPF is often reported as a percentage of the delivered (ex-actuator) dose, but it is equally valid (and common practice) to describe FPFs as a percentage of the labelled dose. When comparing different ICS/LABA products, the labelled dose (e.g. BDP/FORM: $100 / 6 \mu \mathrm{g}$ ) may be more relevant to prescribers, who may find it more difficult to relate to FPF data expressed for the delivered dose (e.g. BDP/ FORM 84.6/5.0 $\mu \mathrm{g}$ ). Moreover, using the delivered dose could bias results in favour of inefficient delivery systems which have lower delivered doses, or mask flow rate dependent changes to the FPF if the delivered dose is similarly affected by flow rate. 
Unpublished in-house data generated by Chiesi via a next generation impactor, show that BDP/FORM produces a "consistent fine particle distribution" as reflected by a consistent MMAD across flow rates, whereas our study suggested a decrease in MMAD at the higher flow rate. It is possible, as noted earlier, that methodological differences may account for this discrepancy. However, it is important to note that, in their study, the fine particle dose (FPD) for BDP varied from $34 \mu \mathrm{g}$ at $30 \mathrm{~L} / \mathrm{min}$ to $47 \mu \mathrm{g}$ at $60 \mathrm{~L} / \mathrm{min}$, a $38 \%$ relative increase [2]. These data clearly support the findings of the DIFFUSE study that the FPD (and therefore also the FPF) of BDP/FORM is flow rate-dependent. By contrast, both our and Chiesi's data show that FP/FORM produces a consistent FPD across both flow rates $[1,2]$.

The review authors question our statement that particles $<1 \mu \mathrm{m}$ are prone to being exhaled. Several papers state that very small particles can be prone to exhalation $[18,19]$. Submicron particles diffuse by Brownian motion [18] and deposit upon collision with the airway wall. A failure to breath-hold is one of the most common inhalation errors made by patients [8] and the ERS/ISAM taskforce notes that a longer particle residence time (and thus a long breath hold) will result in greater deposition [20]. Hence, our paper notes that very small extra-fine particles $(0.1-1.0 \mu \mathrm{m})$ "are prone to exhalation, especially if the breath hold is insufficient", and we still consider this statement valid and fair and supported by the literature. However, we also advocate that patients hold their breath for as long as is comfortable to maximise deposition of all particle sizes.

In conclusion, in our study FP/FORM produced a high and consistent FPF of approximately $40 \%$ at flow rates of 28.3 and $60.0 \mathrm{~L} / \mathrm{min}$, whereas the FPF was flow rate- dependent for other products tested [1]. Our study was fair, robust and appropriate: all inhalers were tested under identical conditions using industry standard methods, apparatus and analyses, consistent with European Pharmacopoeia and specific to the molecules analysed [16]. In their review, the authors question our findings and note that in-house studies show BDP/FORM has a consistent particle size distribution (i.e. MMAD) at flow rates of 28-30 and $60 \mathrm{~L} / \mathrm{min}$ [2]. However, their own data clearly demonstrate that the FPD, and therefore FPF, of BDP/FORM is flow ratedependent. This is in line with, and is supportive of, our findings.

\section{ACKNOWLEDGMENTS}

All named authors meet the ICMJE criteria for authorship for this manuscript, take responsibility for the integrity of the work as a whole, and have given final approval for the version to be published.

Conflict of interest. B. Johal is an employee of Mundipharma Research Limited, J Marshall an employee of Mundipharma International Limited, M Howald an employee of Skyepharma AG, M Fischer an employee of Skyepharma AG and G Venthoye an employee of Skyepharma AG.

Compliance with ethics. The content of this letter is based on previously conducted studies, and does not involve any new studies of human or animal subjects performed by any of the authors.

Open Access. This article is distributed under the terms of the Creative Commons Attribution Noncommercial License which permits any noncommercial use, distribution, 
and reproduction in any medium, provided the original author(s) and the source are credited.

\section{REFERENCES}

1. Johal B, Howald M, Fischer M, Marshall J, Venthoye G. Fine particle profile of fluticasone propionate/ formoterol fumarate versus other combination products: the DIFFUSE study. Comb Prod Ther. 2013;3:39-51.

2. De Maria R, Zagnoni I, Bodria A, et al. Foster ${ }^{\circledR}$ : a high-efficiency combination metered-dose inhaler with consistent particle size distribution at alternative flow rates. Comb Prod Ther. 2014;4:1-5. doi:10.1007/s13556-013-0006-6.

3. Chiesi Ltd. Fostair 100/6 micrograms per actuation pressurised inhalation solution. http://www. medicines.org.uk/emc/medicine/21474/XPIL/Fostair+ $100+6+$ inhalation+solution/. 2013. Accessed 04 April 2014.

4. Mundipharma International Ltd. Flutiform 50 microgram $/ 5$ microgram, 125 microgram/5 microgram and 250 microgram/10 microgram per actuation pressurised inhalation, suspension. http://www.medicines.org.uk/emc/medicine/26957/ $\mathrm{XPIL} /$ flutiform $+50+$ microgram $+5+$ microgram $\% 2 \mathrm{c}+$ $125+$ microgram $+5+$ microgram + and $+250+$ microgram $+10+$ microgram + per + actuation + pressurised + inhalation $\% 2 c+$ suspensions/. 2013. Accessed 04 April 2014.

5. Clement Clarke International Ltd. In-Check DialInstructions for Use. http://www.clement-clarke. com/Portals/0/1902806-In-Check\%20DIAL\%206T\& S-iss3.pdf. 2014. Accessed 04 April 2014.

6. Hesselink AE, Penninx BW, Wijnhoven HA, Kriegsman DM, van Eijk JT. Determinants of an incorrect inhalation technique in patients with asthma or COPD. Scand J Prim Health Care. 2001;19:255-60.

7. Al-Showair RA, Tarsin WY, Assi KH, Pearson SB, Chrystyn H. Can all patients with COPD use the correct inhalation flow with all inhalers and does training help? Respir Med. 2007;101:2395-401.

8. Molimard M. How to achieve good compliance and adherence with inhalation therapy. Curr Med Res Opin. 2005;21(Suppl 4):S33-7.

9. Zagnoni I, De Maria R, Bonelli S, Dagli Alberi M, Bodria A, Ronca B. Comparative analysis of in vitro performance of two pMDI fixed dose combinations. Am J Respir Crit Care Med. 2013;187:A2609.
10. Rattanupatam T, Srichana T. Budesonide dry powder for inhalation: effects of leucine and mannitol on the efficiency of delivery. Drug Deliv. 2014. doi:10.3109/10717544.2013.868555 [Epub ahead of print]

11. Xu Z, Mansour HM, Mulder T, McLean R, Langridge J, Hickey AJ. Dry powder aerosols generated by standardized entrainment tubes from drug blends with lactose monohydrate: 1 . Albuterol sulfate and disodium cromoglycate. J Pharm Sci. 2010;99: $3398-414$.

12. Hassan MS, Lau R. Inhalation performance of pollen-shape carrier in dry powder formulation with different drug mixing ratios: comparison with lactose carrier. Int J Pharm. 2010;386:6-14.

13. Tarsin W, Assi KH, Chrystyn H. In-vitro intra- and inter-inhaler flow rate-dependent dosage emission from a combination of budesonide and eformoterol in a dry powder inhaler. J Aerosol Med. 2004;17: 25-32.

14. Mahesh Kumar T, Misra A. Formulation and evaluation of insulin dry powder for inhalation. Drug Dev Ind Pharm. 2006;32:677-86.

15. Zagnoni I, De Maria R, Bonelli S, Dagli Alberi M, Bodria A, Ronca B. Comparative analysis of in vitro performance of two pMDI fixed dose combinations. Poster presented at the American Thoracic Society 2013 International Conference; 2013 May 17-22; Philadelphia, PA, USA.

16. European Directorate for the Quality of Medicines \& Healthcare, 2.9.18 Preparations for inhalation: aerodynamic assessment of fine particles, in European Pharmacopoeia 7.8. 2010, Council of Europe. p 274.

17. Copley Scientific Ltd. Copley Scientific inhaler brochure: quality solutions for inhaler testing. http://issuu.com/pyramidpress/docs/inhaler_brochure_2012? $=6944369 / 2147040$. 2012. Accessed 04 April 2014.

18. Heyder J. Deposition of inhaled particles in the human respiratory tract and consequences for regional targeting in respiratory drug delivery. Proc Am Thorac Soc. 2004;1:315-20.

19. Newman SP. Aerosol deposition considerations in inhalation therapy. Chest. 1985;88(2 Suppl):152S$60 S$.

20. Laube BL, Janssens HM, de Jongh FH, et al. What the pulmonary specialist should know about the new inhalation therapies. Eur Respir J. 2011;37:1308-417. 